\title{
The side population phenomenon enriches for designated adrenocortical progenitor cells in mice
}

\author{
Urs Lichtenauer, Igor Shapiro, Simone Sackmann ${ }^{1}$, Jacques Drouin ${ }^{2}$, Jürgen Scheele ${ }^{3}$, Matthias Maneck ${ }^{4}$, \\ Christoph Klein ${ }^{4}$ and Felix Beuschlein
}

\author{
Endocrine Research Unit, Medizinische Klinik und Poliklinik IV, Klinikum der Universität München, Ziemssenstraße 1, D-80336 Munich, Germany \\ ${ }^{1}$ Institute of Molecular Medicine and Cell Research, Albert-Ludwigs-University Freiburg, Freiburg, Germany \\ ${ }^{2}$ Laboratoire de Génetique Moléculaire, Institut de Recherches Cliniques de Montréal, Montréal, Quebec, Canada \\ ${ }^{3}$ Institut Für Allgemeine Pathologie und Medizinische Klinik I, Universitätsklinikum Freiburg, Freiburg, Germany \\ ${ }^{4}$ Experimental Medicine and Therapy Research, University Hospital Regensburg, Regensburg, Germany \\ (Correspondence should be addressed to F Beuschlein; Email: felix.beuschlein@med.uni-muenchen.de)
}

\begin{abstract}
Somatic adrenal stem cells are believed to reside in the periphery of the adrenal cortex throughout life for organ maintenance. Herein, we used the side population (SP) phenomenon to enrich for these progenitors, which made up to $0 \cdot 01-0 \cdot 64 \%$ of the total cell count. Microarray analysis revealed an expression profile of SP cells, which clearly differed from that of non-SP cells. However, a promising adrenal specific stem cell marker could not be identified. In vitro, SP cells could be maintained in long-term culture, whereas non-SP cells did not proliferate. After 4 weeks of culturing, immunohistochemistry revealed the expression of steroidogenic enzymes such as $3 \beta-\mathrm{HSD}$, StAR, and P450SCC, suggesting spontaneous differentiation. Interestingly, the quantity of SP cells was significantly diminished in
\end{abstract}

Pbx1 haploinsufficient mice, suggesting a stem cell deficit. By contrast, the subcapsular zone of ACTH-deficient Tpit ${ }^{-1-}$ mice was significantly wider compared with wild-type adrenals (Tpit ${ }^{-1-} 259 \pm 10 \cdot 7$ vs Tpit ${ }^{+/-} 100 \pm 12 \cdot 3 \%$; $P<0 \cdot 01)$. Accordingly, the number of SP cells in these mice was significantly higher $\left(\right.$ Tpit $^{-/-} 0 \cdot 45 \pm 0 \cdot 16$ vs $^{T_{p i t}}{ }^{+/-}$ $0 \cdot 13 \pm 0 \cdot 04 \% ; P<0 \cdot 004)$. ACTH treatment of these animals reverted the subcapsular zone width and the SP fraction back to normal $(130 \pm 10 \cdot 2 \% ; P=0.33$ and $0.09 \%)$, providing indirect evidence for a stem cell 'arrest' in Tpit $^{-1-}$ mice and the role of ACTH in adrenocortical stem cell modulation and differentiation.

Journal of Endocrinology (2012) 215, 383-391

\section{Introduction}

According to the migration theory, each zone of the adult adrenal cortex is derived from a common pool of stem cells located in the periphery of the cortex, which, for organ maintenance and replenishment, migrates centripetally and populates the inner cortical zones upon differentiation (Kim et al. 2009, Wood \& Hammer 2011). In fact, an increasing body of evidence supports this notion: first, tritiated thymidine tracing studies reveals centripetal migration of adrenocortical cells from outer to inner layers (Taki \& Nickerson 1985). Secondly, after enucleation of rat adrenals leaving behind the capsule only, the adrenal cortex regrows and re-forms all three adrenocortical zones (Engeland \& Levay-Young 1999). Thirdly, unilateral adrenalectomy leads to compensatory adrenal growth of the contralateral side (Engeland et al. 2005) with most of proliferation activity taking place within the subcapsular zone (Beuschlein et al. 2002, Lichtenauer et al. 2007, Schulte et al. 2007). Fourthly, recent studies on Wnt (Kim et al. 2008) and Shh (Ching \& Vilain 2009) signaling within the adrenal cortex have demonstrated particular pathway activity in the subcapsular region. Furthermore, Gli1 tracing shows centripetal displacement throughout the adrenal cortex (Huang et al. 2010). In addition, capsular Gli1-positive, Sf1-negative cells gave rise to Sf1-positive, steroidogenic enzyme expressing cells throughout the adrenal cortex, providing genetic evidence that differentiated cells derive from progenitors that reside underneath the capsule (King et al. 2009). Despite these advances in adrenal developmental biology, both identification of adequate adrenal stem cell markers and isolation or enrichment of adrenal stem cells, allowing further in depth characterization, have been unsuccessful thus far.

There is convincing data that isolating the side population (SP), which is based on Hoechst 33342 dye exclusion, leads to an enrichment of progenitor or stem cells in the hematopoietic system (Goodell et al. 1996) and multiple other tissues, including skin, muscle, liver, brain, lung, testes, endometrium, heart, and pituitary (Kim \& Morshead 2003, Montanaro et al. 2003, Wulf et al. 2003, Martin et al. 2004, Meeson et al. 2004, Majka et al. 2005, Umemoto et al. 2006, Xu et al. 2011, Gremeaux et al. 2012, Sandstedt et al. 2012). 
This phenomenon is believed to be attributed to membranebased pumps, in particular ABCG2 and MDR1 that are mainly expressed in stem and progenitor cells. The presence of these pumps renders cells capable of Hoechst dye exclusion, resulting in a distinct small population stained less intense 'by the side' upon FACS analysis (Goodell et al. 1996, Zhou et al. 2001). Interestingly, disruption of the sonic hedgehog pathway by cyclopamine has led to significant reduction of SP cells (Bar et al. 2007), and ABCG2 has been proposed as a regulator of sonic hedgehog signaling (Balbuena et al. 2011), further indicating an interaction between stem cell properties and the SP phenomenon.

Herein, in the absence of well-characterized adrenal stem cell marker genes, we employed the SP technique on mouse adrenals and investigated its suitability for enriching adrenocortical progenitor cells and for identifying adrenal specific stem cell markers. SP cells isolated were analyzed regarding their growth and self-renewal potential, expression pattern, and potential regulatory mechanisms.

\section{Materials and Methods}

\section{Animal models}

All experiments involving animals were performed in accordance with institutionally approved and current animal care guidelines. Animals were maintained under standard conditions of temperature $\left(22^{\circ} \mathrm{C}\right)$ and lighting $(12 \mathrm{~h}$ light: $12 \mathrm{~h}$ darkness) and with food and water given ad libitum. Eight- to 24-week-old Bl/6 wild-type animals (C57Bl/6, Jackson Laboratory, Bar Harbor, ME, USA) were used for adrenal single-cell suspensions. Generation of $\mathrm{Pb} \times 1^{-1-}$ (Luo et al. 1994) and Tpit ${ }^{-1-}$ (synonym: Tbx19-/-) animals (Pulichino et al. 2003) has been described elsewhere. $P b \times 1^{+/-}$haploinsufficient and wild-type mice were obtained by breeding $P b \times 1^{+/-}$mice with $\mathrm{Bl} / 6$ wild-type animals. Tpit $^{+/-}$animals, which have been shown to be indistinguishable from wild-type littermates (Pulichino et al. 2003), were used as controls for Tpit ${ }^{-1-}$ mice. For ACTH stimulation experiments, Tpit ${ }^{-/-}$mice received $30 \mu \mathrm{g}$ per injection of ACTH1-24 in a slow release formula (Synacthen depot, Novartis) i.p. once daily for 10 days. Thereafter, animals were killed and adrenals harvested and prepared for FACS analysis, as described below.

Adrenal preparation, single-cell suspension, primary cell culture, and culture conditions

For primary cultures of mouse adrenals, organs were cleaned of surrounding fat, connective tissue, and large blood vessels. Thereafter, tissue samples were minced into pieces smaller than $0.5 \mathrm{~mm}$ using a razor blade. Minced samples were transferred into $50 \mathrm{ml}$ Falcon tubes, spun down at $600 \mathrm{~g}$ for $5 \mathrm{~min}$, and rinsed twice with fresh PBS. Digestion was performed with $1 \mathrm{mg}$ collagenase II (Biochrom, Berlin,
Germany) per milliliter of PBS at $37^{\circ} \mathrm{C}$ for $50 \mathrm{~min}$ in a shaking water bath. Cell suspension was pipetted up and down at least twice during the incubation time. After digestion, pure FCS was added to a minimum concentration of $10 \%$ in order to inactivate the collagenase, followed by a centrifugation step as described earlier. Cell pellets were resuspended in erythrocyte lysis buffer and incubated for $7 \mathrm{~min}$ at room temperature. After another centrifugation step, cells were resuspended in 5-10 $\mathrm{ml}$ culture medium depending on the expected cell count (DMEM/F12 with 10\% FCS, $3.1 \mathrm{~g} / 1$ glucose, $15 \mathrm{mM}$ HEPES, and $10 \mu \mathrm{l} / \mathrm{ml}$ Pen/Strep, all from Gibco) and sequentially filtered through a 100 and $70 \mu \mathrm{m}$ nylon mesh respectively. Cells were counted using a Neubauer counting chamber and further processed.

\section{Hoechst staining and FACS sorting}

Murine single-cell suspensions were transferred into DMEM high-glucose medium (Gibco) containing 2\% FCS and $10 \mathrm{mM}$ HEPES and stained with the fluorescent dye Hoechst 33342 (Sigma) at a concentration of $5 \mu \mathrm{g} / \mathrm{ml}$ at $37^{\circ} \mathrm{C}$ for $90 \mathrm{~min}$ as described (Goodell et al. 2005). After the staining procedure, propidium iodine $(2 \mu \mathrm{g} / \mathrm{ml}$; Sigma $)$ was added to the samples for identification and exclusion of dead cells. Cell analysis and sorting were performed on a triple-laser cell sorter (MoFlo, Dako (formerly Cytomation), Fort Collins, CO, USA). The Hoechst dye was excited at $350 \mathrm{~nm}$ using an argon ion laser. Emission wavelengths were detected at $450 \mathrm{~nm}$ using a 450/20 bandpass filter and above $675 \mathrm{~nm}$ using a $675 \mathrm{LP}$ filter. The SP was defined as described (Goodell et al. 2005), including the verification procedure with verapamil (Sigma), with the only difference that special care was taken to exclusively isolate the tip of the SP cell fraction.

\section{Microarray analysis}

Microarray analysis was performed for SP vs non-SP adrenal cells of eight male Bl/6 wt mice. To ensure optimal cell quality and purity, FACS sort gates were set restrictively at the most representative areas of SP and non-SP populations. Taken into account the limited number of SP cells resulting from such stringent selection criteria, gene array analysis was performed on a platform, designed for very small cell numbers (Klein et al. 2005).

Data preprocessing was done in $\mathrm{R}$ using the limma package (Smyth \& Speed 2003). Raw probe intensities were background corrected by applying the 'normexp' method. Only cy5 intensities were used. Loess normalization was used in $M$ vs A plots of individual cy5 intensities of transcripts in one array and the median cy5 intensity across all arrays of the same transcript. Log2 ratios were calculated from the normalized intensities and quantile normalization was applied for normalization across arrays. All further analysis is based on normalized log-ratios.

The expression of genes was compared between the SP and non-SP samples by applying regularized linear models in a paired setting as implemented in the limma package 
(Smyth 2004). Genes were considered to be significantly differentially expressed if their adjusted $P$ value (corrected for multiple testing as proposed by Benjamini and Hochberg) was $\leq 0 \cdot 05$. Each group contained eight samples.

\section{cDNA synthesis and semiquantitative $M C-2$ receptor $P C R$}

RNA from cell preparations was extracted using the Qiagen RNA mini kit (Qiagen) following the instructions of the manufacturer. cDNA was transcribed using a RT kit (Promega) and $1.0 \mu \mathrm{g}$ total RNA. For PCR (Promega Taq), 10 pmol of each primer (MC-2 receptor: F, CTGCCACGAGGCTTAAGATAAC and R, GCCTGTCAAGCATTAGTGACAA; nucleotides 663-1150; annealing temperature $58{ }^{\circ} \mathrm{C}$ ) were used. PCR conditions were denaturated at $94^{\circ} \mathrm{C}$ for $2 \mathrm{~min}$, followed by 30 cycles of amplification (each consisting of denaturation for $30 \mathrm{~s}$ at $94{ }^{\circ} \mathrm{C}$, annealing for $30 \mathrm{~s}$ at $58^{\circ} \mathrm{C}$, and extension for $40 \mathrm{~s}$ at $72{ }^{\circ} \mathrm{C}$ ). A final extension for $5 \mathrm{~min}$ at $72{ }^{\circ} \mathrm{C}$ was included. The product was run and analyzed on a $1 \%$ agarose gel.

\section{Culture conditions for adrenal SP cells}

SP and non-SP cells were sorted directly into separate wells of 24-well plates (Sarstedt, Nürnbrecht, Germany). When the cells reached $80 \%$ confluency, cells were trypsinized and subsequently replated in 12 -well plates (BD Falcon, Franklin Lakes, NJ, USA), six-well plates, and $10 \mathrm{~cm}$ dishes (Sarstedt) respectively. All cells were cultivated under the same culture conditions mentioned earlier and pictures were taken using a standard microscope (Leica DMRB).

\section{Tissue staining and immunohistochemistry}

Adrenal SP and non-SP cells were grown on coverslips (Becton Dickinson, Franklin Lakes, NJ, USA) for 1 week and fixated with PFA for at least $1 \mathrm{~h}$. Tissue slides and coverslips were subsequently investigated by hematoxylin and eosin (H\&E) staining. For immunohistochemical analysis, coverslips were blocked with $0 \cdot 3 \% \mathrm{H}_{2} \mathrm{O}_{2}$ in methanol for $10 \mathrm{~min}$ and incubated with blocking buffer for $15 \mathrm{~min}$. Anti-P450Scc, Star, and $3 \beta-H s d$ primary rabbit antibodies (generously provided by Dr Walter Miller, UCSF, CA, USA) were incubated overnight at $4{ }^{\circ} \mathrm{C}$ after dilution in blocking buffer containing 3\% BSA (Sigma), 5\% goat serum (Jackson ImmunoResearch Laboratories, West Grove, PA, USA), and 0.5\% Tween 20 (Calbiochem, San Diego, CA, USA). After rinsing for $15 \mathrm{~min}$ in PBS, secondary antibody (goat anti-rabbit biotinylated IgG; Vector Laboratories, Burlingame, CA, USA) was applied for $30 \mathrm{~min}$ at RT. Bound primary antibody was detected using the VECTASTAINE Elite ABC Kit (Vector Laboratories) according to the manufacturer's protocol.

For localization studies, adrenals from C57Bl/ 6 adult wildtype mice were cut into half and incubated according to the SP staining protocol. Thereafter, adrenals were shock frozen in liquid nitrogen and sliced using a cryomicrotome. After $5 \mathrm{~min}$ of
PFA fixation and PBS washing, Yo-Pro-1 Iodine (Molecular Probes, Eugene, OR, USA) was added in a concentration of $10 \mathrm{nmol} / \mathrm{ml}$ for $3 \mathrm{~h}$. Slides were subsequently analyzed using a standard fluorescence microscope (Leica DM2500).

\section{Measurement of subcapsular zone width in Tpit animals}

For morphological evaluation of adrenals from Tpit animals, sections were dehydrated, embedded in paraffin, sectioned, and stained with H\&E following standard procedures. $3 \beta-H S D$ immunohistochemistry as described earlier and H\&E-stained adrenal sections from heterozygous $\mathrm{Tpit}^{+/-}$and $\mathrm{Tpit}^{-/-}$mice were examined with a standard light microscope using $400 \times$ magnification and pictures were taken. The area beneath the organ capsule containing $3 \beta$-HSD-negative cells was quantified using Image J Software (NIH, Bethesda, MD, USA) and compared between the groups. Morphometric analysis for quantification of the subcapsular zone width was performed on at least three individual animals per genotype as described earlier (Lichtenauer et al. 2007).

\section{Statistical analysis}

Statistical analyses of the microarray are described separately. All other results are expressed as mean \pm s.E.M. Statistical comparisons were analyzed on the basis of Student's $t$ and ANOVA tests using StatView 5 (SAS Institute, Inc., Cary, NC, USA). Statistical significance was defined as $P<0 \cdot 05$ and is indicated as an asterisk ( $\left.{ }^{\star}\right)$ in the figures.

\section{Results}

\section{Identification of the adrenal SP}

After successful identification of SP cells in murine bone marrow specimen (Fig. 1A) in accordance with the staining procedure originally described by Goodell et al. (2005), we adopted the technique for murine adrenocortical cell preparations. The adrenal SP fraction made up to $0 \cdot 01-0 \cdot 64 \%$ (mean $0 \cdot 23 \pm 0 \cdot 04 \%$ ) of the total cell population and was reliably and reproducibly detectable (Fig. 1B). Unspecific staining was excluded by co-incubating with verapamil, which by blocking the responsible cell membrane channels prevents Hoechst dye exclusion and leads to a disappearance of cells within the predefined FACS gate (Fig. 1C). Double nuclear staining of wild-type adrenal glands with Hoechst 33342, according to the SP staining protocol, and YoPro revealed several cells in the periphery of the adrenal cortex that were clearly YoPro positive, but not, or barely positive for Hoechst 33342, possibly resembling adrenal SP cells (Fig. 1D).

\section{Characterization of the adrenal SP}

Microarray analysis was carried out with very stringent selection criteria for SP and non-SP cells. The expression 

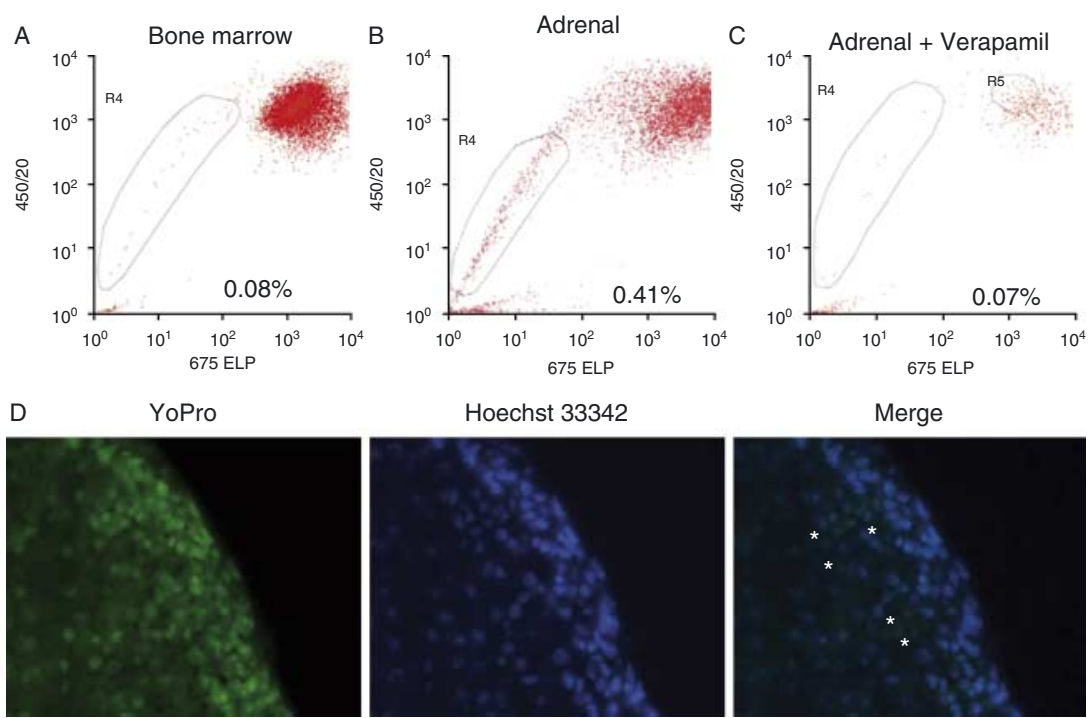

Figure 1 Side population (SP) staining. FACS analysis of Hoechst 33342-stained cells and identification of SP cells in wild-type murine bone marrow used as a positive control (A) and in wild-type adrenal glands (B and C). The proportion of SP cells was largely diminished upon co-incubation with verapamil (C). YoPro and Hoechst 33342 double staining renders several Hoechst-negative, YoPro-positive cells in the periphery of the adrenal cortex (D). Full colour version of this figure available via http://dx.doi.org/10.1530/JOE-12-0393.

profile of the two cell populations was clearly different (Fig. 2A) and a classifier could be trained that separated the two groups without error. However, none of the genes analyzed was differentially expressed in a manner to be considered a marker with potential value for detection of adrenocortical cells with stem cell properties. Nevertheless, Fgf2 and Gli1, but also Gli3, Shh, and $\beta$-catenin tended to be upregulated, while SF1 tended to be downregulated in
A

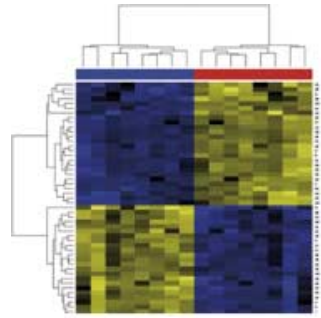

C

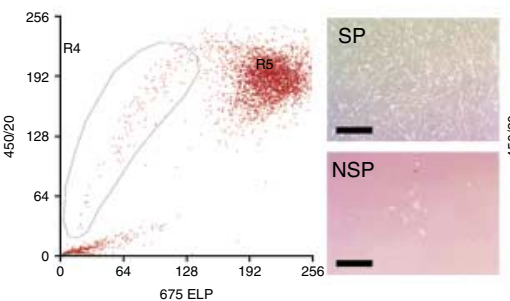

B
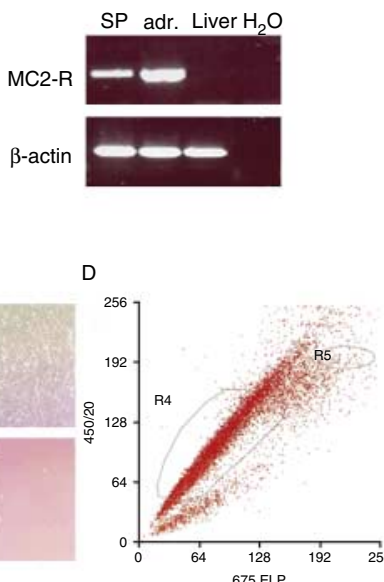
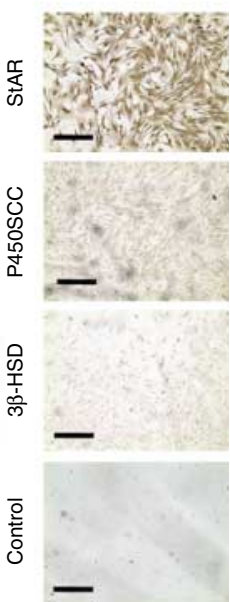

Figure 2 Characterization of adrenal side population (SP) cells. Heatmap of microarray analysis of SP vs non-SP cells with evident differential gene expression between the two cell populations (A). Semiquantitative PCR analysis reveals MC2 receptor expression in adrenal SP cells; adr., wild-type adrenal; liver, MC2 receptor-negative control tissue; $\mathrm{H}_{2} \mathrm{O}$, negative water control (B). FACS-sorted murine adrenal glands upon Hoechst 33342 staining after long-term in vitro culture indication proliferation of SP cells only (C). FACS re-analysis (D) of cultured cells and immunohistochemical staining for StaR, P450SCC, and $3 \beta-\mathrm{HSD}$ (and control staining lacking primary antibody) of in vitro-cultivated SP cells (E). Full colour version of this figure available via http://dx.doi.org/10.1530/JOE-12-0393. 


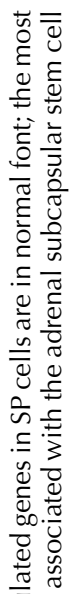

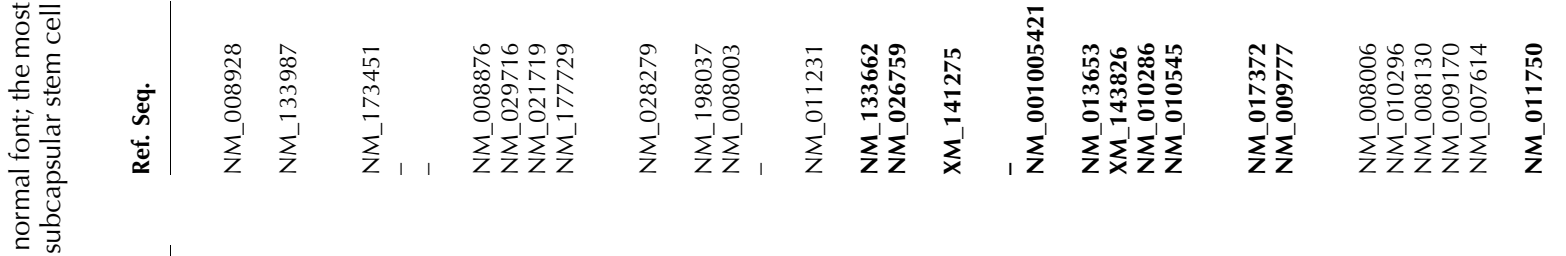
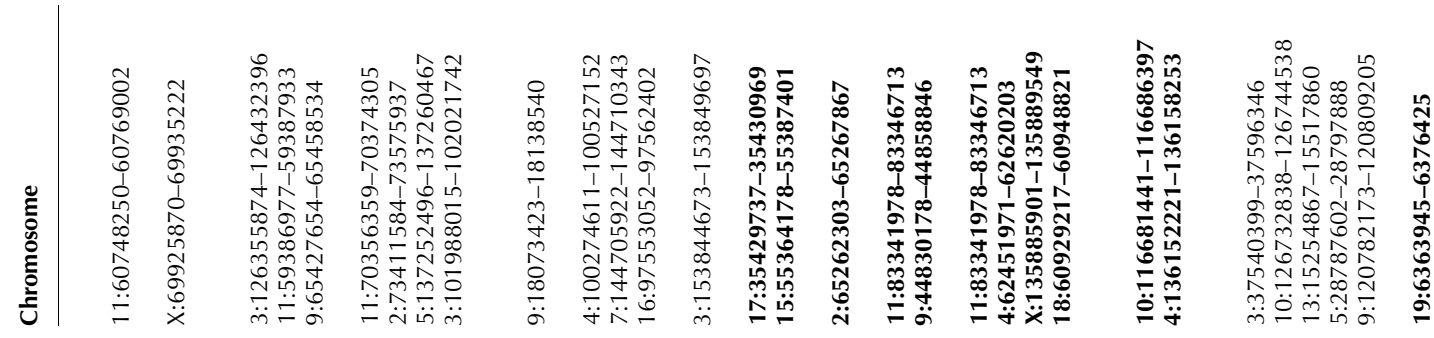

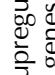

要

垔

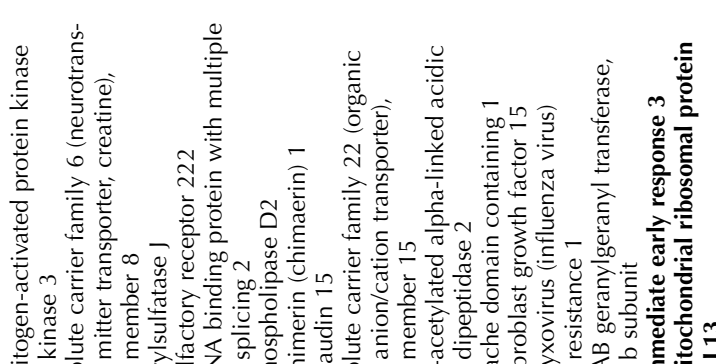

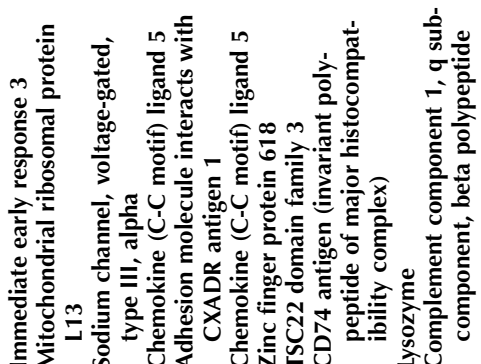

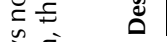

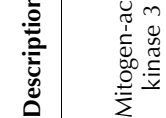

的高

है

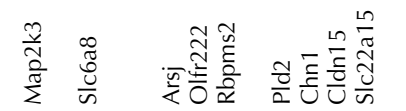

$\frac{\widetilde{c}}{\bar{c}} \frac{7}{\tilde{c}}$

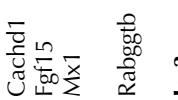

$\stackrel{m}{\underline{\underline{a}}} \frac{m}{\frac{2}{2}}$

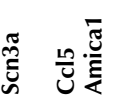

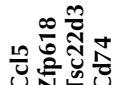

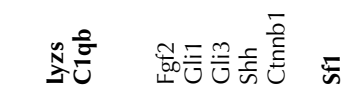

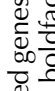

品.

훙
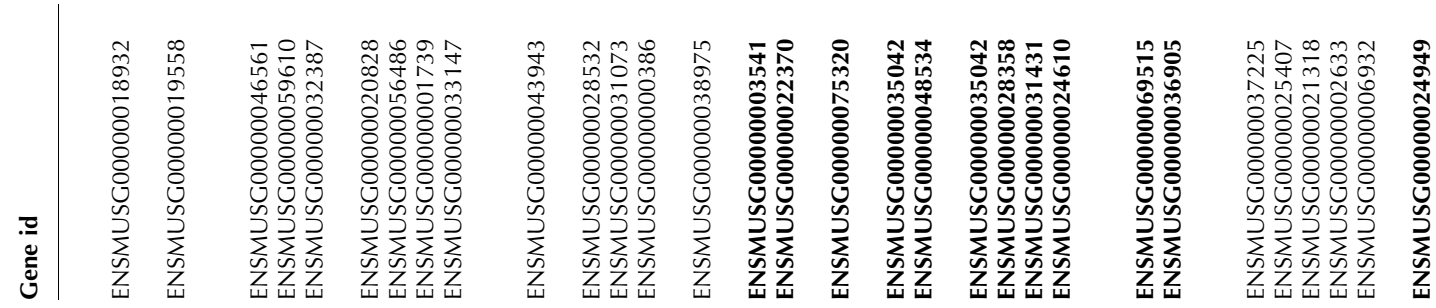

क्षित

ह

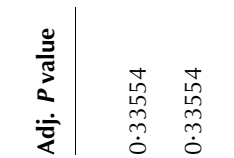

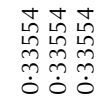

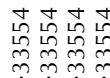

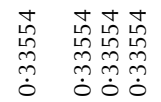

喜嘉

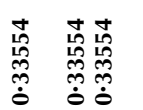

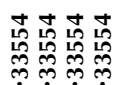

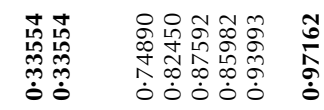

은

웡

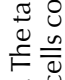

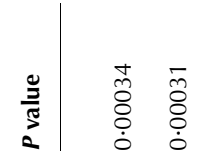

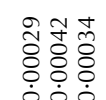

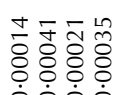

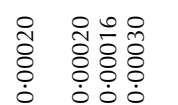

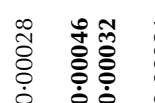

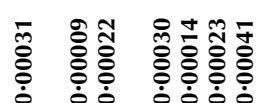

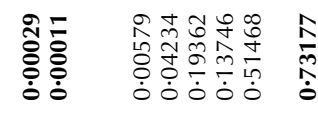

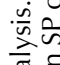

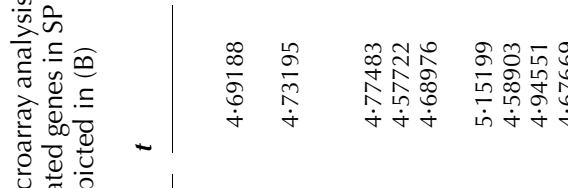

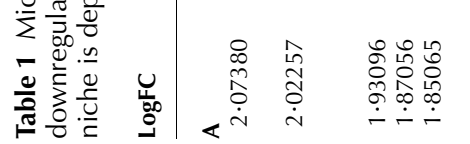

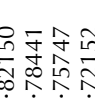

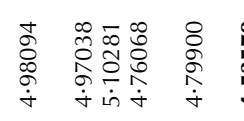

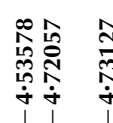

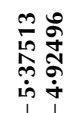

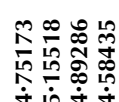

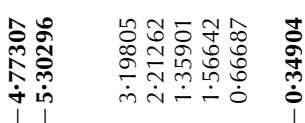


SP cells. Genes with the highest expression differences between the two groups are depicted in Table 1 (normal font: upregulated in SP; bold fontface: downregulated in $\mathrm{SP}$, in accordance with heatmap). Semiquantitative analysis revealed the expression of the MC-2 receptor in adrenal SP cells (Fig. 2B).

After FACS sorting and plating of murine adrenal cells in 24-well plates, SP cells repeatedly grew in vitro in an adherent manner over several passages, while non-SP cells adhered, but did not display any growth potential (Fig. 2C). FACS re-analysis of cultured SP cells demonstrated the presence of a mixture of both SP (18.65\%; Fig. 2D) and non-SP cells upon culturing. Immunohistochemistry performed on SP cell cultures grown on coverslips for further 4 weeks revealed the expression of several steroidogenic enzymes such as $3 \beta-\mathrm{HSD}$, p450SCC, and StAR on the protein level (Fig. 2E). Immunohistochemical analysis of non-SP cells was not possible, as these cells did not replicate.

\section{SP in Pbx1 haploinsufficient mice}

Pbx1 - in synergy with Sf1 - plays a critical role for proper adrenal development (Zubair et al. 2006, Lichtenauer et al. 2007). Pbx1 haploinsufficient mice have been demonstrated to have smaller adrenals and a lower proliferation rate of adrenocortical cells. We, therefore, compared the proportion of SP cells from normal murine adrenals with those of $P b x 1$ haploinsufficient animals. Interestingly, FACS analyses consistently revealed a significant lower number of SP cells in $P b \times 1^{+/-}$adrenals $(0 \cdot 10 \pm 0 \cdot 04 \%)$ in comparison with wild-type animals $(0 \cdot 32 \pm 0 \cdot 04 \%, P<0 \cdot 01$; Fig. 3$)$.

\section{SP in Tpit knockout mice}

Tpit (Tbx19) knockout animals have been used as a model of secondary adrenal insufficiency (Pulichino et al. 2003). Interestingly, in the absence of pituitary $\mathrm{ACTH}, \mathrm{Tpit}^{-1-}$ animals displayed a significantly enlarged subcapsular zone in comparison with Tpit ${ }^{+/-}$controls $(259 \cdot 3 \pm 10 \cdot 7$ vs $100 \cdot 0 \pm 12 \cdot 3 \%, P=0 \cdot 02$; Fig. 4A). Likewise, the fraction of $\mathrm{SP}$ cells in those mice was significantly higher compared with wild-type animals $(0 \cdot 38 \pm 0 \cdot 07$ vs $0 \cdot 13 \pm 0 \cdot 02 \%, P<0 \cdot 01$; Fig. 4B). I.p. application of ACTH in Tpit ${ }^{-1-}$ mice over a period of 10 days resulted in a normalization of the subcapsular zone width $(130 \cdot 1 \pm 10 \cdot 2 \%, P=0 \cdot 24$; Fig. 4 A) as well as the number of SP cells detectable (0.09\%; Fig. 4B).

\section{Discussion}

Although great advances have been achieved in localizing and characterizing the adrenal stem cell niche and molecular pathways involved, it was not yet possible to identify suitable adrenal specific stem cell markers. Taken into account that these designated progenitors are not expected to express the generally accepted embryonic markers of pluripotent cells,
A
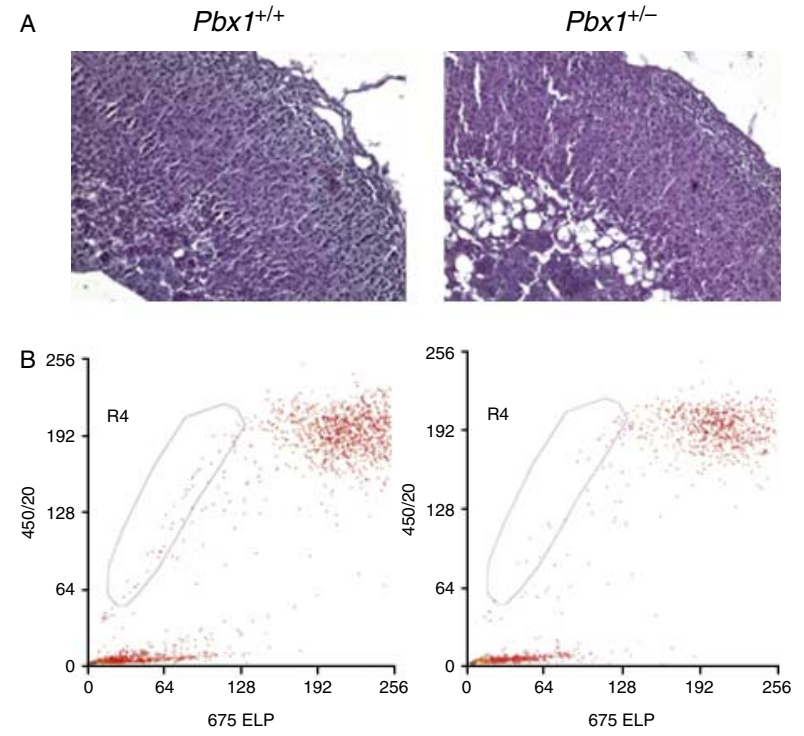

C

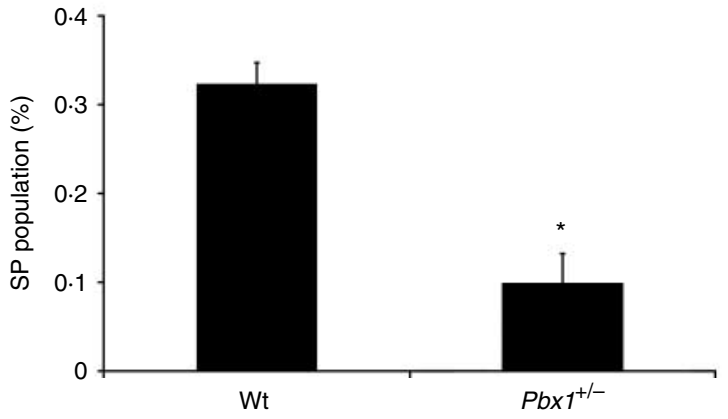

Figure 3 Side population (SP) cells in the context of Pbx1 haploinsufficiency. Morphological examination upon H\&E staining (A), representative FACS analysis (B), and quantification of SP cells $(\mathrm{C})$ in wild-type animals $\left(\mathrm{Pbx}^{+/++}\right)$and heterozygous littermates $\left(P b \times 1^{+1-}\right)$, indicating a significantly smaller proportion of SP cells in the context of $P b x 1$ haploinsufficiency. ${ }^{*} P<0 \cdot 05$. Full colour version of this figure available via http://dx.doi.org/ 10.1530/JOE-12-0393.

there is a great variety of different progenitor marker candidates to be considered. This is further complicated by the fact that these genes are often differently expressed in different tissues. Furthermore, in the adrenal gland, even other genes might be of importance. In the absence of known adrenal specific stem cell markers, we took advantage of the fact that the SP phenomenon was found suitable to enrich for progenitor cells in a variety of different organs. Thereby, we aimed at investigating the suitability of the SP procedure for the enrichment and characterization of murine adrenocortical progenitor cells, possibly resulting in the identification of tissue-specific adrenal progenitor markers.

After establishing the SP technique on adrenocortical tumor cells (Lichtenauer et al. 2008), SP cells could be readily detected in mouse adrenals that made up to $0 \cdot 01-0 \cdot 64 \%$ of the total cell population. Furthermore, co-incubation of 

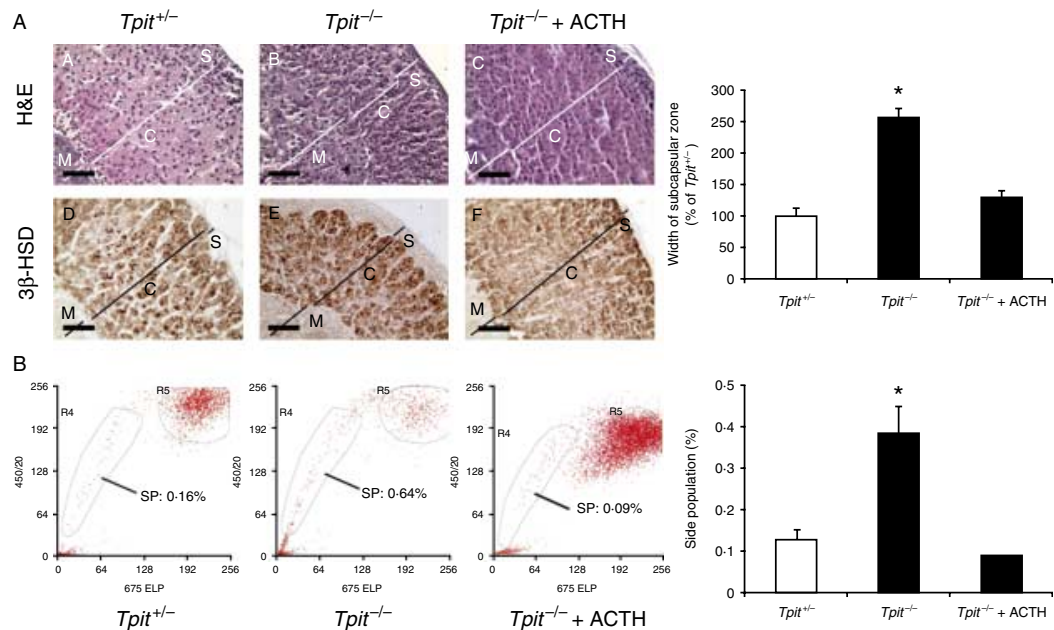

Figure 4 Side population (SP) in Tpit knockout mice. Tpit ${ }^{-/-}$mice present with a

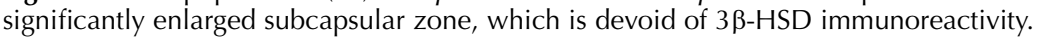
Subcapsular zone width of this can be normalized by ACTH treatment $(\mathrm{A})$.

These phenotypic alterations are paralleled by concomitant changes in the proportion of adrenal SP cells (B). ${ }^{*} P<0 \cdot 05$. Full colour version of this figure available via http://dx.doi.org/10.1530/JOE-12-0393.

murine adrenal cells with the calcium channel blocker verapamil rendered SP cells undetectable upon FACS analysis. Adrenal SP cells, therefore, fulfilled in number and appearance the validation criteria established for other tissue preparations (Goodell et al. 2005). Interestingly, double staining of frozen adrenal sections with YoPro revealed several Hoechst-negative cells in the periphery of the adrenal cortex, possible resembling the localization of the adrenal SP cells.

Although the SP method is well established for detecting and enriching progenitor cells or stem cells from the hematopoietic system and a variety of other tissues, great caution has to be taken in interpreting the results, as the positive identification of SP cells does not inevitably guarantee stemness. In fact, we could demonstrate earlier that SP cells within the adrenocortical tumor cell line NCIh295R have similar functional properties in comparison with non-SP cells (Lichtenauer et al. 2008). Thus, further thorough and tissue-specific evaluations should be pursued for the identification of alternative reliable stem cell markers.

In consequence, we employed whole genome microarray analysis on SP vs non-SP cells to discover potential adrenal specific stem cell markers. Very stringent selection criteria were applied to ensure the best possible separation of the two populations. Owing to the limited number of SP cells available, microarray analysis was performed on a platform optimized for small cell numbers (Klein et al. 2005). Although the expression profile of SP vs non-SP cells clearly differed, subtle expression changes could be found for sets of genes only, but not for individual genes, a mandatory prerequisite for the positive identification of suitable adrenal progenitor markers. However, genes known to be relevant for adrenal stem cell maintenance, especially Fgf2 and Gli1, but also Shh and $\beta$-catenin, tended to be upregulated, while Sf1, as the major transcription factor for adrenal differentiation, seemed to be downregulated in SP cells. The finding that these genes were not significantly altered in SP cells could be attributed to the fact that SP cells still represent a rather heterogeneous cell population, with progenitor cells - although enriched - still being a minority, resulting in less differential expression of SP cells compared with non-SP cells. Along the same line, novel adrenal progenitor markers might have been underscored and overlooked upon microarray data interpretation.

The potential of adrenal SP cells to proliferate was assessed upon FACS sorting and in vitro cultivation in standard adrenal cell culture medium. As expected for a proposed cell population with stem cell-like properties, SP cells continued to grow over multiple passages within a period of several months, whereas non-SP cells could not be maintained following the same culturing conditions. This experiment foremost demonstrates the self-renewing capabilities of adrenal SP cells. In addition, the appearance of non-SP cells during long-term culturing also suggests asymmetric cell division which, together with the low proliferative potential of non-SP cells, might have resulted in the observed ratio of distinct cell populations.

When grown on a coverslip and subjected to immunohistochemistry, adrenal SP cells stained positive for a variety of adrenocortical markers such as steroidogenic enzymes, indicating spontaneous differentiation under in vitro culture conditions. Owing to the limited number of SP cells obtainable from five pooled mice adrenals (maximum of 5000 cells), in vitro expansion was a prerequisite for 
immunohistochemistry, so that the analysis of earlier time points was technically not possible. We were not able to detect any relevant expression of embryonic stem cell markers (Oct4 and Sox2) on the basis of real-time PCR analysis (data not shown). This was not unexpected, as our cells were never exposed to media supplements or culture conditions routinely used for maintenance of embryonic stem cells, allowing a selection bias toward a less differentiated phenotype. Furthermore, well-characterized somatic cell populations, such as mesenchymal stem cells, also do not spontaneously express embryonic marker genes (Baddoo et al. 2003, Pochampally et al. 2004).

To investigate potential regulators of adrenocortical SP cells, we analyzed $P b x 1$ haploinsufficient and Tpit knockout mice - the former characterized in detail by our group elsewhere (Lichtenauer et al. 2007). Adrenals in the context of $P b \times 1$ haploinsufficiency are smaller with concomitant lower proliferation and impaired adrenal function (Lichtenauer et al. 2007). Interestingly, compared with wild-type animals, the number of SP cells in $P b x 1^{+/-}$mice was significantly smaller, providing indirect evidence for a stem cell deficit in the context of $P b x 1$ haploinsufficiency. By contrast, Tpit ${ }^{-/-}$ mice, which are ACTH deficient, present with an adrenal subcapsular zone, which is substantially wider in comparison with wild-type adrenals. This morphological feature has been reported for animals with disrupted ACTH signaling, i.e. ACTH receptor knockout mice (Chida et al. 2007), which also display an enlargement of the subcapsular zone. Based on the immunohistochemical analysis in Tpit ${ }^{-1-}$ mice, this zone is mainly populated by non-steroidogenic cells. Interestingly, this morphological feature is paralleled by a significantly higher number of SP cells in adrenals of Tpit $^{-/}$mice in comparison with their wild-type littermates. Furthermore, ACTH treatment of knockout animals not only reverted the subcapsular zone width back to normal but also resulted in a reduction of the SP fraction to a level similar to that of wild-type animals. In contrast, higher levels of ACTH in $P b \times 1^{+/-}$mice (Lichtenauer et al. 2007) might be involved in driving the adrenal stem cell pool toward differentiation reducing the number of dormant progenitors in the subcapsular zone. Taken together, these findings provide indirect evidence that $\mathrm{ACTH}$, in addition to its well-known action on steroidogenesis, might also modulate adrenocortical stem cell maintenance and fate. In accordance with this theory, we found the MC2 receptor expressed in adrenal SP cells.

In conclusion, adrenal SP cells are likely to be located within the subcapsular stem cell zone, they are able to proliferate and self-renew. The expression profile, which is similar to non-SP, mainly population cells, suggests an enrichment of rather designated direct adrenocortical progenitors. Along the same line, the detection of typical steroidogenic enzymes in long-term in vitro cultured SP cells indicates spontaneous differentiation. Finally, ACTH is suggested to play an important role as a regulator for adrenal SP and progenitor cells.

\section{Declaration of interest}

The authors declare that there is no conflict of interest that could be perceived as prejudicing the impartiality of the research reported.

\section{Funding}

The study was supported by Landesstiftung Baden-Wuerttemberg grant P-LS-ASN/5 (to F B) and by an internal grant (FöFoLe Förderprojekt Reg. no. 624 to U L). Furthermore, the work was part of the postgraduate $\mathrm{MD}-\mathrm{PhD}$ program of $\mathrm{U} \mathrm{L}$ at the ZMMK of the University of Cologne. The authors are indebted to Dr Walter Miller (UCSF, CA) for his generous gift of adrenal specific antibodies.

\section{Acknowledgements}

The authors would like to thank Ms. Isabell Blochberger from Experimental Medicine and Cell Research in Regensburg for microarray hybridization and quality management.

\section{References}

Baddoo M, Hill K, Wilkinson R, Gaupp D, Hughes C, Kopen GC \& Phinney DG 2003 Characterization of mesenchymal stem cells isolated from murine bone marrow by negative selection. Journal of Cellular Biochemistry 89 1235-1249. (doi:10.1002/jcb.10594)

Balbuena J, Pachon G, Lopez-Torrents G, Aran JM, Castresana JS \& Petriz J 2011 ABCG2 is required to control the sonic hedgehog pathway in side population cells with stem-like properties. Cytometry. Part A 79 672-683.

Bar EE, Chaudhry A, Lin A, Fan X, Schreck K, Matsui W, Piccirillo S, Vescovi AL, DiMeco F, Olivi A et al. 2007 Cyclopamine-mediated hedgehog pathway inhibition depletes stem-like cancer cells in glioblastoma. Stem Cells 25 2524-2533. (doi:10.1634/stemcells.2007-0166)

Beuschlein F, Mutch C, Bavers DL, Ulrich-Lai YM, Engeland WC, Keegan C \& Hammer GD 2002 Steroidogenic factor-1 is essential for compensatory adrenal growth following unilateral adrenalectomy. Endocrinology 143 3122-3135. (doi:10.1210/en.143.8.3122)

Chida D, Nakagawa S, Nagai S, Sagara H, Katsumata H, Imaki T, Suzuki H, Mitani F, Ogishima T, Shimizu C et al. 2007 Melanocortin 2 receptor is required for adrenal gland development, steroidogenesis, and neonatal gluconeogenesis. PNAS 104 18205-18210. (doi:10.1073/pnas. 0706953104)

Ching S \& Vilain E 2009 Targeted disruption of sonic hedgehog in the mouse adrenal leads to adrenocortical hypoplasia. Genesis 47 628-637. (doi:10.1002/dvg.20532)

Engeland WC \& Levay-Young BK 1999 Changes in the glomerulosa cell phenotype during adrenal regeneration in rats. American Journal of Physiology 276 R1374-R1382.

Engeland WC, Ennen WB, Elayaperumal A, Durand DA \& Levay-Young BK 2005 Zone-specific cell proliferation during compensatory adrenal growth in rats. American Journal of Physiology. Endocrinology and Metabolism 288 E298-E306. (doi:10.1152/ajpendo.00307.2004)

Goodell MA, Brose K, Paradis G, Conner AS \& Mulligan RC 1996 Isolation and functional properties of murine hematopoietic stem cells that are replicating in vivo. Journal of Experimental Medicine 183 1797-1806. (doi:10.1084/jem.183.4.1797)

Goodell MA, McKinney-Freeman S \& Camargo FD 2005 Isolation and characterization of side population cells. Methods in Molecular Biology 290 343-352.

Gremeaux L, Fu Q, Chen J \& Vankelecom H 2012 Activated phenotype of the pituitary stem/progenitor cell compartment during the early-postnatal maturation phase of the gland. Stem Cells and Development 21 801-813. (doi:10.1089/scd.2011.0496) 
Huang CC, Miyagawa S, Matsumaru D, Parker KL \& Yao HH 2010 Progenitor cell expansion and organ size of mouse adrenal is regulated by sonic hedgehog. Endocrinology 151 1119-1128. (doi:10.1210/ en.2009-0814)

Kim M \& Morshead CM 2003 Distinct populations of forebrain neural stem and progenitor cells can be isolated using side-population analysis. Journal of Neuroscience 23 10703-10709.

Kim AC, Reuter AL, Zubair M, Else T, Serecky K, Bingham NC, Lavery GG, Parker KL \& Hammer GD 2008 Targeted disruption of $\beta$-catenin in Sf1-expressing cells impairs development and maintenance of the adrenal cortex. Development 135 2593-2602. (doi:10.1242/dev.021493)

Kim AC, Barlaskar FM, Heaton JH, Else T, Kelly VR, Krill KT, Scheys JO, Simon DP, Trovato A, Yang WH et al. 2009 In search of adrenocortical stem and progenitor cells. Endocrine Reviews 30 241-263. (doi:10.1210/er.2008-0039)

King P, Paul A \& Laufer E 2009 Shh signaling regulates adrenocortical development and identifies progenitors of steroidogenic lineages. PNAS 106 21185-21190. (doi:10.1073/pnas.0909471106)

Klein CA, Zohlnhofer D, Petat-Dutter K \& Wendler N 2005 Gene expression analysis of a single or few cells. Current Protocols in Human Genetics Chapter 1118 (Unit 11)

Lichtenauer UD, Duchniewicz M, Kolanczyk M, Hoeflich A, Hahner S, Else T, Bicknell AB, Zemojtel T, Stallings NR, Schulte DM et al. 2007 Pre-B-cell transcription factor 1 and steroidogenic factor 1 synergistically regulate adrenocortical growth and steroidogenesis. Endocrinology 148 693-704. (doi:10.1210/en.2006-0681)

Lichtenauer UD, Shapiro I, Geiger K, Quinkler M, Fassnacht M, Nitschke R, Ruckauer KD \& Beuschlein F 2008 Side population does not define stem cell-like cancer cells in the adrenocortical carcinoma cell line NCI h295R. Endocrinology 149 1314-1322. (doi:10.1210/en.2007-1001)

Luo X, Ikeda Y \& Parker KL 1994 A cell-specific nuclear receptor is essential for adrenal and gonadal development and sexual differentiation. Cell 77 481-490. (doi:10.1016/0092-8674(94)90211-9)

Majka SM, Beutz MA, Hagen M, Izzo AA, Voelkel N \& Helm KM 2005 Identification of novel resident pulmonary stem cells: form and function of the lung side population. Stem Cells 23 1073-1081. (doi:10.1634/stemcells. 2005-0039)

Martin CM, Meeson AP, Robertson SM, Hawke TJ, Richardson JA, Bates S, Goetsch SC, Gallardo TD \& Garry DJ 2004 Persistent expression of the ATP-binding cassette transporter, Abcg2, identifies cardiac SP cells in the developing and adult heart. Developmental Biology 265 262-275. (doi:10. 1016/j.ydbio.2003.09.028)

Meeson AP, Hawke TJ, Graham S, Jiang N, Elterman J, Hutcheson K, Dimaio JM, Gallardo TD \& Garry DJ 2004 Cellular and molecular regulation of skeletal muscle side population cells. Stem Cells 22 1305-1320. (doi:10.1634/stemcells.2004-0077)

Montanaro F, Liadaki K, Volinski J, Flint A \& Kunkel LM 2003 Skeletal muscle engraftment potential of adult mouse skin side population cells. PNAS 100 9336-9341. (doi:10.1073/pnas.1133179100)

Pochampally RR, Smith JR, Ylostalo J \& Prockop DJ 2004 Serum deprivation of human marrow stromal cells (hMSCs) selects for a subpopulation of early progenitor cells with enhanced expression of OCT-4 and other embryonic genes. Blood 103 1647-1652. (doi:10.1182/blood2003-06-1967)
Pulichino AM, Vallette-Kasic S, Tsai JP, Couture C, Gauthier Y \& Drouin J 2003 Tpit determines alternate fates during pituitary cell differentiation. Genes and Development 17 738-747. (doi:10.1101/gad.1065703)

Sandstedt J, Jonsson M, Kajic K, Sandstedt M, Lindahl A, Dellgren G, Jeppsson A \& Asp J 2012 Left atrium of the human adult heart contains a population of side population cells. Basic Research in Cardiology 107255. (doi:10.1007/s00395-012-0255-7)

Schulte DM, Shapiro I, Reincke M \& Beuschlein F 2007 Expression and spatio-temporal distribution of differentiation and proliferation markers during mouse adrenal development. Gene Expression Patterns 7 72-81. (doi:10.1016/j.modgep.2006.05.009)

Smyth GK 2004 Linear models and empirical bayes methods for assessing differential expression in microarray experiments. Statistical Applications in Genetics and Molecular Biology 3 Article 3. (doi:10.2202/ 1544-6115.1027)

Smyth GK \& Speed T 2003 Normalization of cDNA microarray data. Methods 31 265-273. (doi:10.1016/S1046-2023(03)00155-5)

Taki TM \& Nickerson PA 1985 Differentiation and proliferation of adrenocortical cells during the early stages of regeneration. Laboratory Investigation $\mathbf{5 3}$ 91-100.

Umemoto T, Yamato M, Nishida K, Yang J, Tano Y \& Okano T 2006 Limbal epithelial side-population cells have stem cell-like properties, including quiescent state. Stem Cells 24 86-94. (doi:10.1634/stemcells. 2005-0064)

Wood MA \& Hammer GD 2011 Adrenocortical stem and progenitor cells: unifying model of two proposed origins. Molecular and Cellular Endocrinology 336 206-212. (doi:10.1016/j.mce.2010.11.012)

Wulf GG, Luo KL, Jackson KA, Brenner MK \& Goodell MA 2003 Cells of the hepatic side population contribute to liver regeneration and can be replenished with bone marrow stem cells. Haematologica 88 368-378.

Xu J, Hu FF, Cui YG, Luo J, Jiang CY, Gao L, Qian XQ, Mao YD \& Liu JY 2011 Effect of estradiol on proliferation and differentiation of side population stem/progenitor cells from murine endometrium. Reproductive Biology and Endocrinology 9 103. (doi:10.1186/1477-7827-9-103)

Zhou S, Schuetz JD, Bunting KD, Colapietro AM, Sampath J, Morris JJ, Lagutina I, Grosveld GC, Osawa M, Nakauchi H et al. 2001 The ABC transporter Bcrp1/ABCG2 is expressed in a wide variety of stem cells and is a molecular determinant of the side-population phenotype. Nature Medicine 7 1028-1034. (doi:10.1038/nm0901-1028)

Zubair M, Ishihara S, Oka S, Okumura K \& Morohashi K 2006 Two-step regulation of Ad4BP/SF-1 gene transcription during fetal adrenal development: initiation by a Hox-Pbx1-Prep1 complex and maintenance via autoregulation by Ad4BP/SF-1. Molecular and Cellular Biology 26 4111-4121. (doi:10.1128/MCB.00222-06)

\section{Received in final form 2 October 2012 Accepted 5 October 2012 Made available online as an Accepted Preprint 5 October 2012}

